\title{
On a Catch-Forecasting Model for the Pink Salmon Oncorhynchus gorbuscha in the Maritime Province of Siberia
}

\author{
Seizo Hasegawa ${ }^{1}$, Naoki Suzuki2 ${ }^{*}$, Kazumi Sakuramoto ${ }^{2}$ \\ ${ }^{1}$ Reseach Institute of Fisheries Science and Technology, Shimonoseki, Japan \\ ${ }^{2}$ Deptartment of Ocean Sciences, Tokyo University of Marine Science and Technology, Tokyo, Japan \\ Email: *naoki@kaiyodai.ac.jp
}

How to cite this paper: Hasegawa, S., Suzuki, N. and Sakuramoto, K. (2017) On a Catch-Forecasting Model for the Pink Salmon Oncorhynchus gorbuscha in the Maritime Province of Siberia. Open Access Library Journal, 4: e3406. https://doi.org/10.4236/oalib.1103406

Received: January 25, 2017

Accepted: March 11, 2017

Published: March 14, 2017

Copyright $\odot 2017$ by authors and Open Access Library Inc.

This work is licensed under the Creative Commons Attribution International License (CC BY 4.0).

http://creativecommons.org/licenses/by/4.0/ cC) (i) Open Access

\begin{abstract}
The aim of this paper is to elucidate the fluctuation mechanism in the catch of pink salmon Oncorhynchus gorbuscha harvested in the Maritime Province of Siberia. We used catch data on pink salmon born in odd- and even-numbered years. Monthly indices of the Arctic Oscillation and the Pacific Decadal Oscillation were used as the environmental factors. We assumed that the catch in year $t, C_{t}$ and that in year $t+2, C_{t+2}$, could be used to represent the spawning stock biomass and recruitment, respectively, and $C_{t+2} / C_{t}$ could then be used to represent the recruitment per spawning stock biomass. Under these assumptions, we adopted the equation $C_{t+2} / C_{t}=g$ (environmental factors) as the model that forecasted the trajectories of the catch. The results were as follows: 1) the trajectories of the catches of pink salmon born in oddand even-numbered years can be well reproduced by the model mentioned above. No density-dependent effect was detected in the relationship between $C_{t+2}$ and $C_{t}$ which corresponds to the stock-recruitment relationship (SRR), for catches in both odd- and even-numbered years. The relationship between $C_{t+2}$ and $C_{t}$ for odd-numbered years showed a clockwise loop; however, that for even-numbered years showed an anticlockwise loop. It is believed that this difference occurs in response to the negative relationship between the catches born in odd- and even-numbered years. Pink salmon is one of the typical fish species to which a density-dependent SRR can be applied; however, this study indicates that the assumption of a density-dependent SRR is not valid.
\end{abstract}

\section{Subject Areas}

Marine Biology 


\section{Keywords}

Density-Dependent Effect, Maritime Province of Siberia,

Oncorhynchus gorbuscha, Pink Salmon, Stock-Recruitment Relationship

\section{Introduction}

One of the most important tasks in fisheries resource management is to elucidate the fluctuation mechanism in fish populations. One of the key factors in those mechanisms is the stock-recruitment relationship (SRR). The typical traditional SRR models are the well-known Ricker model [1] and the Beverton and Holt model [2], which is based on a density-dependent mechanism in SRR. Ricker developed his SRR model to investigate the fluctuation in Salmonidae species [1]. Pink salmon is a typical Salmonidae species; therefore, almost all scientists believe that the SRR of pink salmon follows the Ricker model. Recently, however, the importance of environmental factors has been reported in many studies. For instance, Zhenming et al. [3] noted the presence of significant positive effects of the sea-surface temperature (SST) on the survival rates of northern pink salmon stocks, but weak negative effects of SST on the survival rates of southern pink salmon stocks. Kaeriyama et al. [4] noted that the carrying capacity of pink salmon was synchronous with long-term trends in climate change. Alan and Gus [5] noted that the wild salmon population in the North Pacific Ocean, particularly pink salmon, had grown greatly since the mid-1970s, apparently due to the bottom-up effects of climate change on ocean physics and production processes. However, it is widely believed among scientists in this field that a density-dependent effect is also an important factor in controlling the population [6] [7].

Recently, however, Sakuramoto proposed a new concept of the mechanism of the SRR which did not assume any density-dependent effect [8] [9] [10] [11] [12]. The purpose of the present study is to elucidate whether or not the density-dependent effect is essential to explain the population fluctuation of pink salmon and to propose a new model that can reproduce the population fluctuation of pink salmon.

\section{Materials and Methods}

\subsection{Data}

The data used in this study are shown below: 1) catch in weight for pink salmon landed in the Maritime Province of Siberia from 1950 to 2010 [13]; 2) indices of the Arctic Oscillation (AO) by month from 1948 to 2010 [14]; and 3) indices of the Pacific Decadal Oscillation (PDO) by month from 1948 to 2010 [15].

\subsection{Correlation Coefficient between Catch and AO or Catch and PDO}

We separated the pink salmon catch data into two groups. One is the catch har- 
vested in the odd-numbered year $t$, which is denoted with $C_{t}^{O}$, and another is that harvested in the even-numbered year $t$, which is denoted with $C_{t}^{E}$. We calculated the correlation coefficients between $C_{t}^{O}$ and $\mathrm{AO}$ and between $C_{t}^{O}$ and PDO in month $m(m=1,2, \ldots$, and 12) of year $t-k,(k=0,1$ and 2$)$, and that between $C_{t}^{E}$ and $\mathrm{AO}$ and between $C_{t}^{E}$ and PDO in month $m(m=1$, $2, \ldots$, and 12$)$ of year $t-k,(k=0,1$ and 2$)$.

\subsection{Relationship between $C_{t+2}$ and $C_{t}$}

The eggs of pink salmon are spawned from September to November in year $t$, and they hatch from February to March in year $t+1$. The fries swim downstream to the ocean from April to May in year $t+1$ (Figure 1). They stay in the ocean for about one year, and then they go back to the coastal waters and go upstream in their native rivers from July to August in year $t+2$. Then, they lay their eggs on the bottom of the rivers and die. To summarize the life circle, the spawning stock biomass (SSB) in year $t$ reproduces the SSB of their next generation in year $t+2$. That is, there is a two-year difference between the two generations.

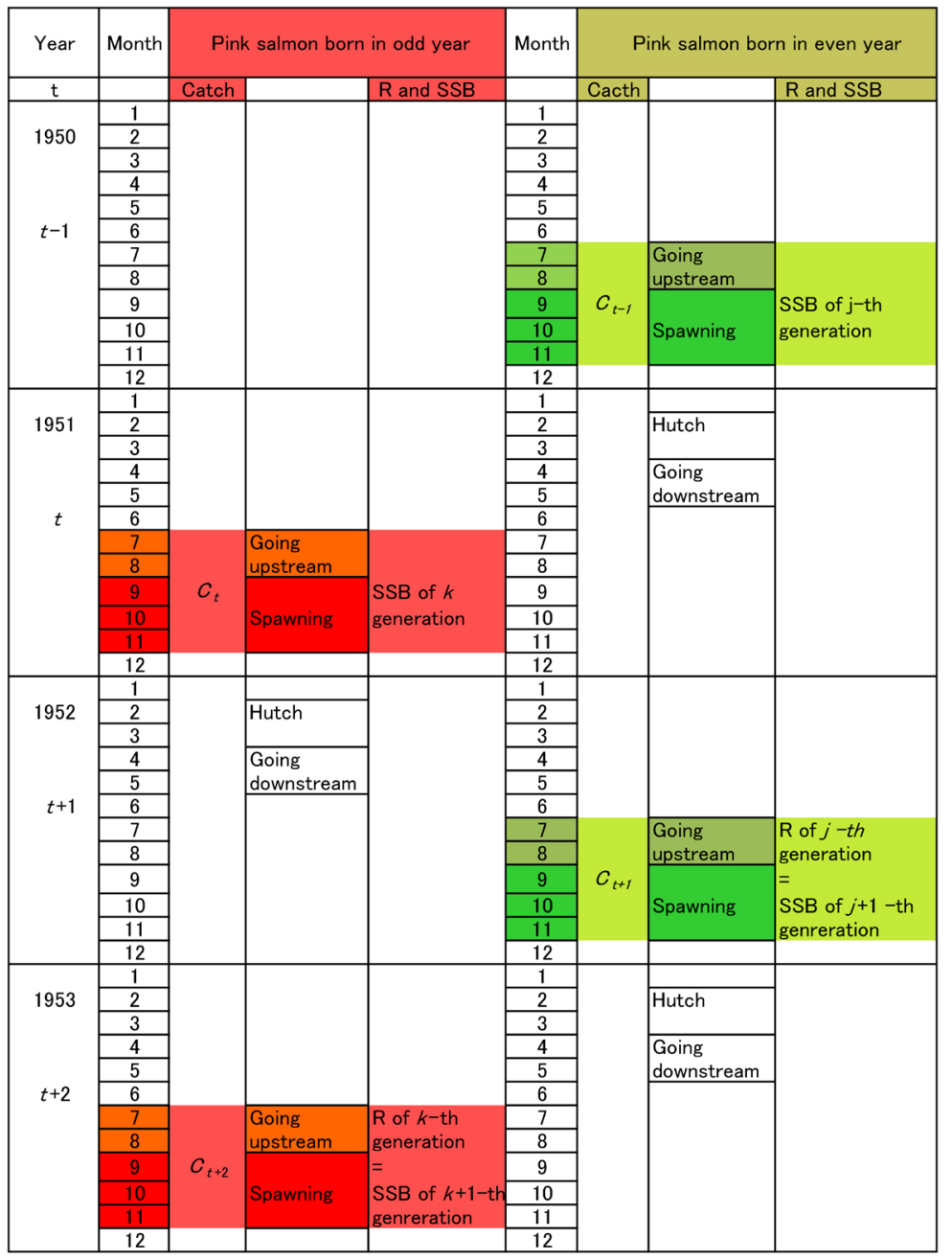

Figure 1. Life histories of pink salmon born in odd- and even-numbered years. 
The abundance of pink salmon in the maritime Province of Siberia has not been estimated, and so we cannot use abundance data directly. However, when the abundance is high, the catches in the coastal waters and in rivers would also be high. Further, when the catches in the coastal waters and in rivers are high, the SSB that has escaped the harvest in the coastal waters and rivers would also be high. Therefore, we can assume that the SSB in year $t\left(S S B_{t}\right)$ is proportional to the catch in year $t\left(C_{t}\right)$. In this study, we assume that $C_{t}$ is proportional to $S S B_{t}$ and the catch in year $t+2\left(C_{t+2}\right)$, is proportional to the recruitment in year $t+2$, $\left(R_{t+2}\right)$, which is reproduced by $S_{S B}$. Therefore, in this study, we assume $S S B_{t} \propto$ $C_{t}$ and $R_{t+2} \propto C_{t+2}$ and we analyze the relationship between $C_{t+2}$ and $C_{t}$ as the $\mathrm{SRR}$, which is the relationship between $R_{t+2}$ and $S S B_{t}$

This study used three regression methods in plotting $\ln \left(C_{t+2}\right)$ against $\ln \left(C_{t}\right)$, i.e., simple regression analysis, Deming regression analysis [16], and Passing and Bablok regression analysis [17]. A simple regression analysis is problematic because it assumes that the independent variable contains no observation errors. Therefore, parameters estimated using a simple regression analysis usually have serious biases [18] [19] [20] [21] [22]. When both independent and dependent variables contain observational errors, the Deming and Passing and Bablok regression analyses can effectively remove the bias inherent in the results of a simple regression analysis. The programs developed by Aoki [23] [24] were used when the Deming and Passing and Bablok regression analyses were applied to the data.

\subsection{Relationship between Catches in Odd- and Even-Numbered Years}

Pink salmon born in odd- and even-numbered years are completely separated genetically, because the years when they born are completely separated. Therefore, there may be some competitive relationship between these two stocks in the same way that different species that inhabit the same area sometimes engage in competition. In order to confirm this possibility, we investigated the relationship in the case when $\ln \left(C_{t+1}^{E}\right)$ was plotted against $\ln \left(C_{t}^{O}\right)$, because there might be a possibility that the fries born in the even-numbered year $t+1$ are eaten by one-year-old fish born in the odd-numbered year $t$. The opposite relationship was also checked. That is, $\ln \left(C_{t}^{O}\right)$ was plotted against $\ln \left(C_{t-1}^{E}\right)$.

\subsection{Forecasting Models for Catch Ratio and Catch}

According to Sakuramoto [9] [11] [12], we tested the following model, which reproduces the trajectories of the catch ratio,

$$
C_{t+2} / C_{\mathrm{t}}=g\left(x_{1}, x_{2}, \ldots, x_{n}\right)
$$

where $x_{1}, x_{2}, \ldots, x_{n}$ denote the environmental factors that control $C_{t+2} / C_{t}$ which corresponds to the R per SSB (RPS). In this model, $n$ denotes the number of environmental factors and $g(\bullet)$ denotes the function that determines how environmental factors affect the ratio $C_{t+2} / C_{t}$. We applied stepwise regression analysis using R software, "stepwlm", to select the optimal model shown in Equation 
(1). Using the estimated values of $C_{t+2} / C_{t}$ we calculated $C_{t+2}$ using the following equation;

$$
C_{t+2}=\exp \left[\left\{\ln \left(C_{t+2} / C_{t}\right)\right\}_{\text {estimated }}\right]\left\{C_{t}\right\}_{\text {observed }}
$$

\section{Results}

\subsection{Correlation Coefficient between Catch and AO or Catch and PDO}

We calculated the correlation coefficients between $C_{t}^{O}$ and $\mathrm{AO}$ and between $C_{t}^{O}$ and PDO in month $m$ of year $t-k\left(k=0,1\right.$ and 2), and those between $C_{t}^{E}$ and $\mathrm{AO}$ and $C_{t}^{E}$ and PDO in month $m$ of year $t-k(k=0,1$ and 2). The AOs and PDOs that showed high correlation coefficients with $p$-values less than 0.10 are shown in Table 1. We used these AOs and PDOs as the candidates for the environmental factors in Equation (1).

\subsection{Relationship between $C_{t+2}$ and $C_{t}$}

Figure 2 shows the relationship between $\ln \left(C_{t+2}^{O}\right)$ and $\ln \left(C_{t}^{O}\right)$, which corresponds to the relationship between $\ln \left(R_{t+2}\right)$ against $\ln \left(S S B_{t}\right)$ for odd-numbered years. The parameters of regression lines estimated by the simple, Deming and

Table 1. AO or PDO by month showing correlation coefficients with $p$-values less than 0.10 . The notations ai and pi denote the indices of AO and PDO by month $\mathrm{i}$, respectively. The mark * indicates the variables selected as the environmental factors in Equation (1).

\begin{tabular}{|c|c|c|c|c|c|c|}
\hline \multicolumn{7}{|c|}{ Odd numbered years } \\
\hline & \multicolumn{3}{|c|}{$\mathrm{AO}$} & \multicolumn{3}{|c|}{ PDO } \\
\hline & Variable & $r$ & $p$-value & Variable & $r$ & $p$-value \\
\hline \multirow[t]{2}{*}{$t$} & $a_{4}^{*}$ & 0.429 & 0.020 & - & - & \\
\hline & $a_{11}^{*}$ & -0.322 & 0.089 & & & \\
\hline$t-1$ & $a_{9}$ & 0.327 & 0.083 & - & - & \\
\hline \multirow[t]{3}{*}{$t-2$} & $a_{2}^{*}$ & -0.410 & 0.027 & $p_{11}$ & -0.324 & 0.087 \\
\hline & $a_{5}^{*}$ & 0.408 & 0.028 & & & \\
\hline & $a_{10}$ & 0.370 & 0.048 & & & \\
\hline \multicolumn{7}{|c|}{ Even-numbered years } \\
\hline & & $\mathrm{AO}$ & & & $\mathrm{PDO}$ & \\
\hline & Variable & $r$ & $p$-value & Variable & $r$ & $p$-value \\
\hline \multirow[t]{2}{*}{$t$} & $a_{4}$ & -0.315 & 0.096 & $p_{1}^{*}$ & -0.334 & 0.076 \\
\hline & $a_{9}$ & -0.329 & 0.081 & & & \\
\hline \multirow[t]{2}{*}{$t-1$} & $a_{4}$ & 0.513 & 0.004 & - & - & \\
\hline & $a_{12}$ & 0.351 & 0.062 & & & \\
\hline \multirow[t]{3}{*}{$t-2$} & $a_{2}^{*}$ & -0.410 & 0.027 & $p_{11}^{*}$ & -0.324 & 0.087 \\
\hline & $a_{5}^{*}$ & 0.408 & 0.028 & & & \\
\hline & $a_{10}$ & 0.370 & 0.048 & & & \\
\hline
\end{tabular}




\section{Odd-numbered years}

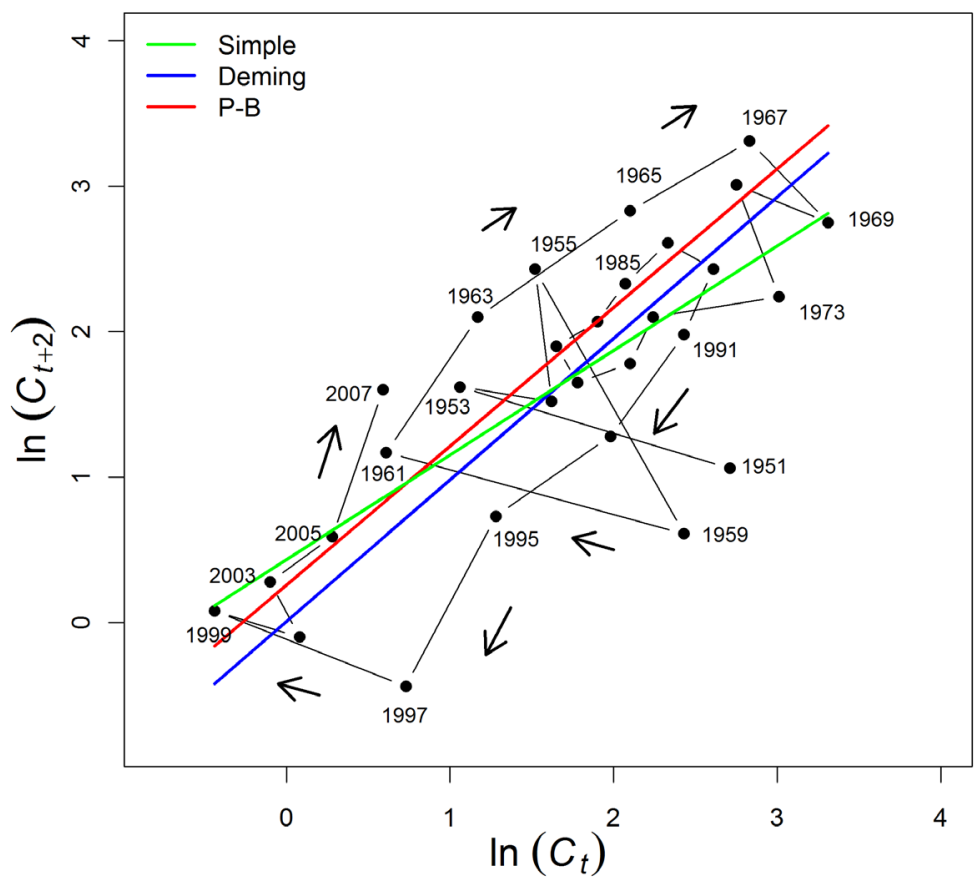

Figure 2. Stock-recruitment relationship for odd-numbered years. We assumed that $S S B_{t}$ $\propto C_{t}$ and $R_{t+2} \propto C_{t+2}$, and we analyzed the relationship between $C_{t+2}$ and $C_{t}$ as the SRR. Three regression methods, the simple, Deming and Passing-Bablok methods, were applied. The figures show the year harvested. A clear clockwise loop is recognized.

Passing-Bablok regression methods are shown in Table 2. The 95\% confidence intervals of the slope determined by the simple, Deming and Passing-Bablok regression methods were $(0.204,0.852),(0.689,1.208)$ and $(0.733,1.470)$, respectively. That is, the slope estimated by the simple regression analysis was statistically less than unity, and it was judged that a density-dependent effect was detected. However, in the results obtained using the Deming and Passing-Bablok regression methods, neither slope was statistically different from unity, and it was judged that a density-dependent effect was not detected. In Figure 2, a clear clockwise loop appeared, a phenomenon that can be explained by the logic proposed by Sakuramoto [8] [10] [11]. That is, the age at maturity is 2 years old, and it is considered that the cycle of environmental condition is much longer than this age at maturity.

Figure 3 shows the relationship between $\ln \left(C_{t+2}^{E}\right)$ and $\ln \left(C_{t}^{E}\right)$, i.e., the relationship between $\ln \left(R_{t+2}\right)$ against $\ln \left(S S B_{t}\right)$ for even-numbered years. The parameters of the regression line estimated by the simple, Deming and PassingBablok regression methods are shown in Table 2. The 95\% confidence intervals of the slope determined by the simple, Deming and Passing-Bablok regression methods were $(0.164,0.876),(0.578,1.592)$ and $(0.430,1.571)$, respectively. That is, the slope estimated by simple regression analysis was statistically less than unity, and it was judged that a density-dependent effect was detected. However, in the results obtained by the Deming and Passing-Bablok regression methods, 


\section{Even-numbered years}

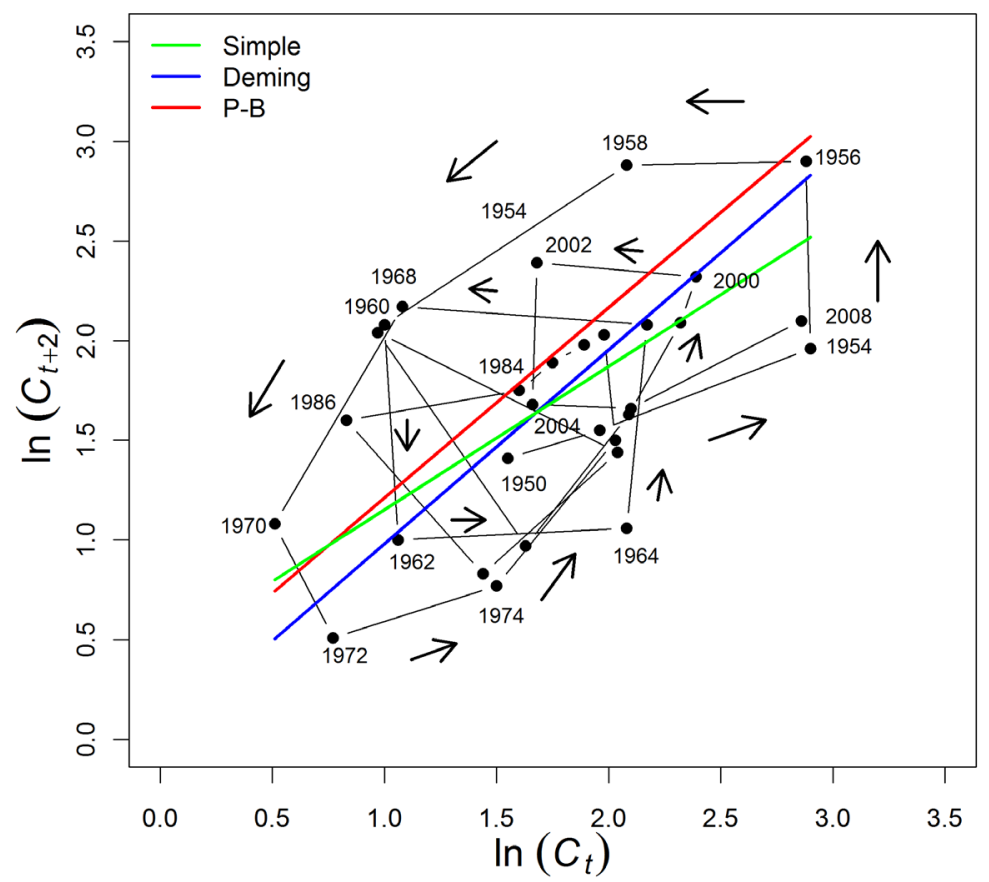

Figure 3. Stock-recruitment relationship for even-numbered years. We assumed that $S S B_{t}$ $\propto C_{t}$ and $R_{t+2} \propto C_{t+2}$, and we analyzed the relationship between $C_{t+2}$ and $C_{t}$ as the SRR. Three regression methods, the simple, Deming and Passing-Bablok methods, were applied. The figures show the year harvested. A clear anticlockwise loop is recognized.

Table 2. Regression line for plotting $C_{t}+2$ against $C_{t}$ which corresponds to the stockrecruitment relationship. Parameters were estimated by the simple, Deming and Passingbablok (P-B) regression methods. No density-dependent effect was detected except when the simple regression method was applied.

\begin{tabular}{|c|c|c|c|c|c|}
\hline \multicolumn{6}{|c|}{ Odd-numbered years } \\
\hline & $a$ & $b$ & 95\% C.L. & & Detection of density effect \\
\hline Simple & 0.738 & 0.528 & $(0.204,0.852)$ & $b<1$ & Detected \\
\hline Deming & -0.0669 & 0.918 & $(0.689,1.208)$ & $b=1$ & Not detected \\
\hline P-B & -0.0418 & 1.021 & $(0.733,1.470)$ & $b=1$ & Not detected \\
\hline \multicolumn{6}{|c|}{ Even-numbered years } \\
\hline & a & $\mathrm{b}$ & 95\% C.L. & & \\
\hline Simple & 0.87 & 0.52 & $(0.164,0.876)$ & $b<1$ & Detected \\
\hline Deming & 0.0518 & 1.015 & $(0.578,1.592)$ & $b=1$ & Not detected \\
\hline P-B & -0.153 & 1.117 & $(0.430,1.571)$ & $b=1$ & Not detected \\
\hline
\end{tabular}

the slopes were not statistically different from unity, and it was judged that no density-dependent effect was detected. In Figure 3, a clear anticlockwise loop can be recognized, which is opposite what would be expected according to the logic proposed by Sakuramoto [8] [10] [11]. That is, the age at maturity is the same for pink salmon born in odd-numbered years ( 2 years old), so that a 
clockwise loop emerges. We will address in the Discussion section why two opposite phenomena occur in the odd- and even-numbered years.

\subsection{Relationship between Catches in Odd- and Even-Numbered Years}

Figure 4 shows the trajectories of the catches, $\ln \left(C_{t+1}^{E}\right)$ and $\ln \left(C_{t}^{O}\right)$. The trajectories seem to have a negative relationship. Figure 5 shows the plots of $\ln \left(C_{t+1}^{E}\right)$ against $\ln \left(C_{t}^{O}\right)$. The slope of the regression lines estimated using the simple and Deming regression analyses are shown in Table 3 . When the dependent variable has a negative relationship to the independent variable, the Passing-Bablok regression method cannot be used. Therefore, only the simple and Deming regression methods were applied in this analysis.

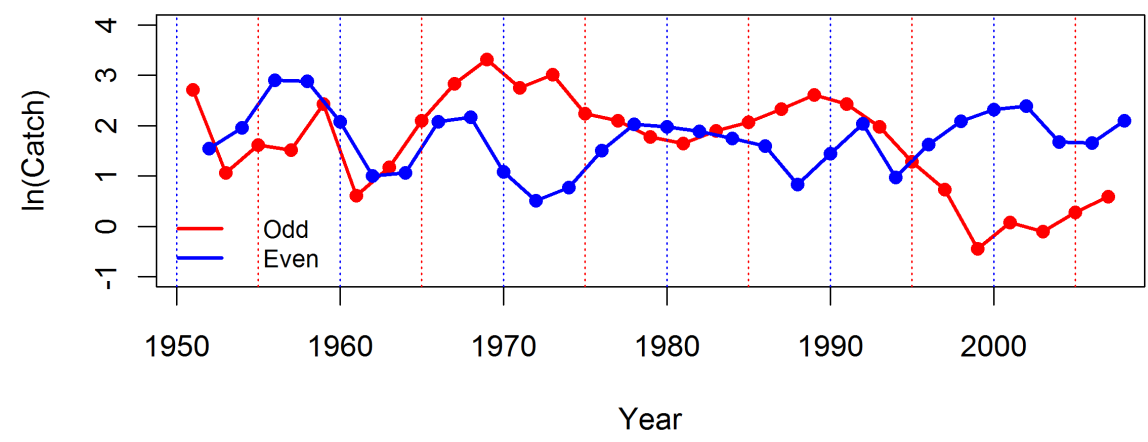

Figure 4. Catch trajectories for odd- and even-numbered years.

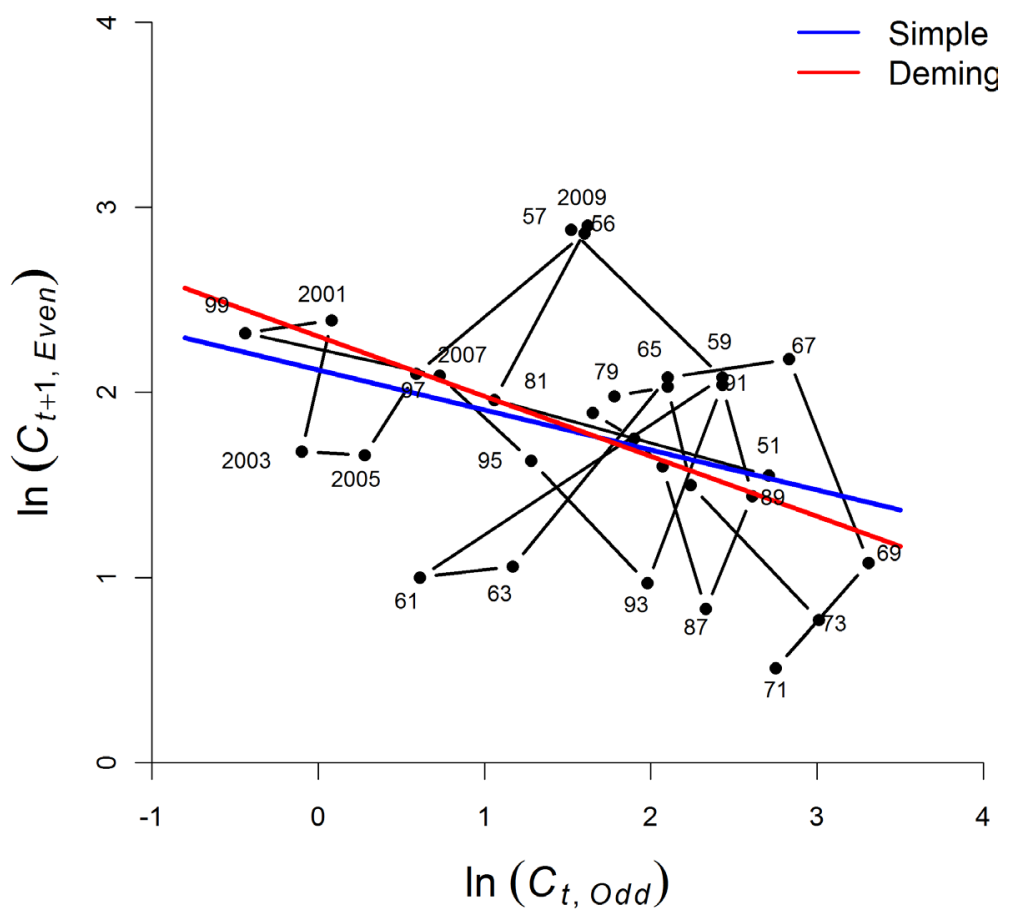

Figure 5. Relationship between catches in odd- and even-numbered years. The slopes of the regression lines that plot $\ln \left(C_{t+1}^{E}\right)$ against $\ln \left(C_{t}^{O}\right)$ were estimated using simple and the Deming regression analyses. 
Table 3. Regression lines of $\ln \left(C_{t+1}\right)$ against $\ln \left(C_{t}\right)$. Parameters were estimated by the simple, Deming and Passing-bablok (P-B) regression analyses.

\begin{tabular}{ccccccc}
\hline \multicolumn{6}{c}{$\ln \left(C_{t+1}\right)$ born in even year $t+1$ against $\ln \left(C_{t}\right)$ born in odd year $t}$. \\
\hline Simple & $a$ & $b$ & $95 \%$ C.L. & & $p$-value & $r$ \\
\hline Deming & 2.122 & -0.216 & $(-0.448,0.0115)$ & $b=0$ & 0.0663 & -0.340 \\
& 2.304 & -0.325 & $(-0.476,-0.088)$ & $b<0$ & & \\
& $\ln \left(C_{t+1}\right)$ born in odd year $t+1$ against $\ln \left(C_{t}\right)$ born in even year $t$ & \\
Simple & $a$ & $b$ & $95 \%$ C.L. & & $p$-value & $r$ \\
Deming & 2.530 & -0.500 & $(-1.113,0.113)$ & $b=0$ & 0.106 & -0.301 \\
\hline
\end{tabular}

The slope was significantly negative with a $10 \%$ significance level $(p=0.0663)$ when the simple regression analysis was applied, and the slope was significantly negative with a $5 \%$ significance level when the Deming regression analysis was applied. That is, we can conclude that $\ln \left(C_{t+1}^{E}\right)$ has a negative relationship with $\ln \left(C_{t}^{O}\right)$. The result of the oppositional relationship, that is, $\ln \left(C_{t}^{O}\right)$ plotted against $\ln \left(C_{t-1}^{O}\right)$ is also shown in Table 3 . The slope was slightly larger than the $10 \%$ significance level $(p=10.6)$ when the simple regression analysis was applied; however, the slope was significantly negative with a $5 \%$ significant level when the Deming regression analysis was applied.

\subsection{Forecasting Models for Catch Ratio and Catch}

In Equation (1), the candidates for the environmental factors are shown in Table 1. Table 1 shows the AOs and PDOs in month $m$ of year $t-k,(k=0,1$, and 2$)$, for which the $p$-values of the correlation coefficients for $C_{t}$ were less than 0.10 . Using these monthly AOs and PDOs, we estimated the optimal model using the stepwise regression analysis in $\mathrm{R}$ software. Here, we assume that $\ln \left(C_{t+2} / C_{t}\right)$ corresponds to $\ln \left(R P S_{t}\right)$.

The results are also shown in Table 1. That is, AOs in April and November in year $t$ and in February and May in year $t-2$ were chosen as the environmental factors for the model forecasting the catch ratio in odd-numbered years. The model estimated was as follows,

$$
\ln (R P S t)=-0.128-0.173 a_{2, t-2}+0.504 a_{5, t-2}+0.404 a_{4, t}-0.356 a_{11, t}
$$

Here $a_{m, t-k}$ denotes the $\mathrm{AO}$ in month $m$ of year $t-k$. The result is shown in Figure 6, and the Akaike information criteria (AIC) of which was-39.26. The catches forecast by Equation (2) are also shown at the bottom of Figure 6.

The AOs in February and May in year $t-2$ and the PDO in January in year $t$ and the PDO in November in year $t-2$ were chosen as the environmental factors for the model forecasting the catch ratio in even-numbered years. That is,

$$
\ln (R P S t)=0.0810+0.116 a_{2, t-1}+0.475 a_{7, t-2}-0.132 a_{1, t}-0.218 a_{12, t-2}
$$

Here $p_{m, t-k}$ denotes the PDO in month $m$ of year $t-k$. The result is shown in Figure 7, and the AIC of which was-37.98. The catches forecast by Equation (2) 

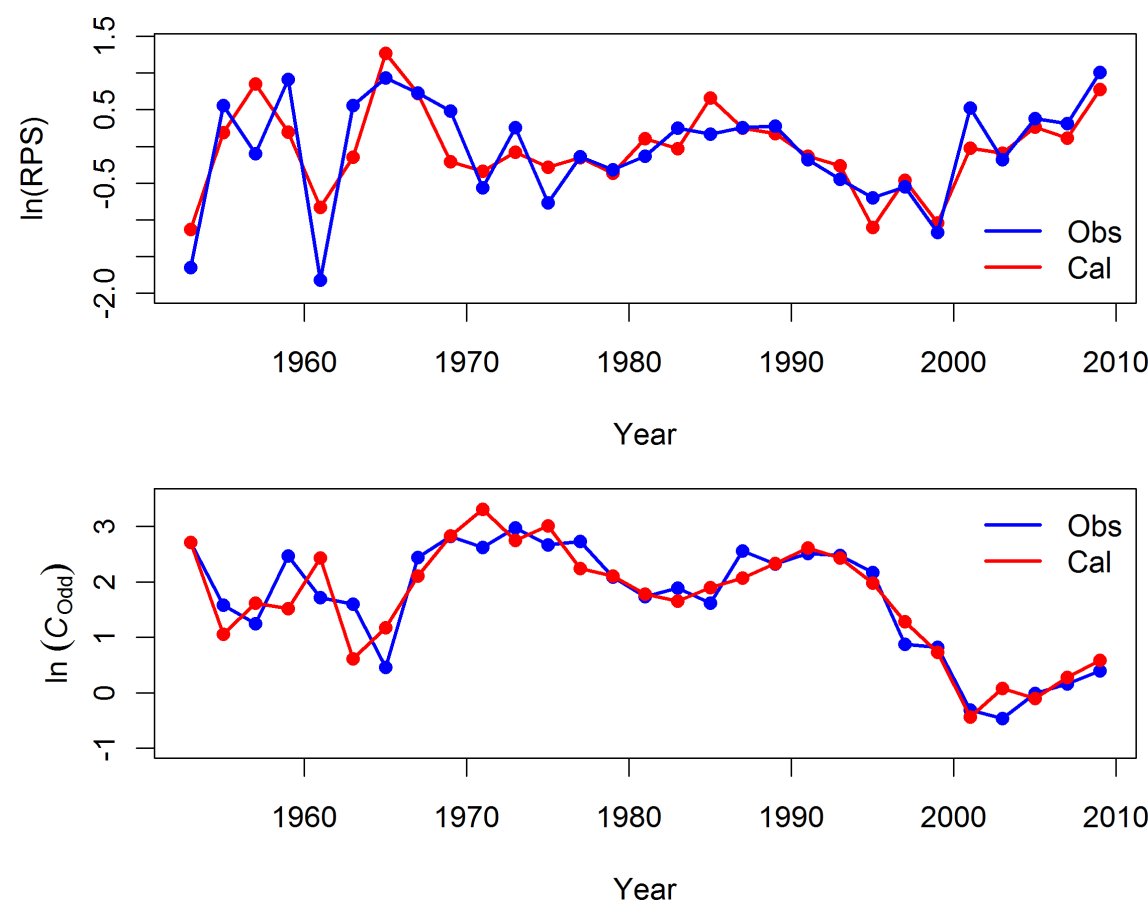

Figure 6. Trajectories of $C_{t+2} / C_{t}$ and $C_{t+2}$ for odd-numbered years. Top: $C_{t+2} / C_{t}$ reproduced by the model shown in Equation (1). Bottom: $C_{t+2}$ reproduced by Equation (2).
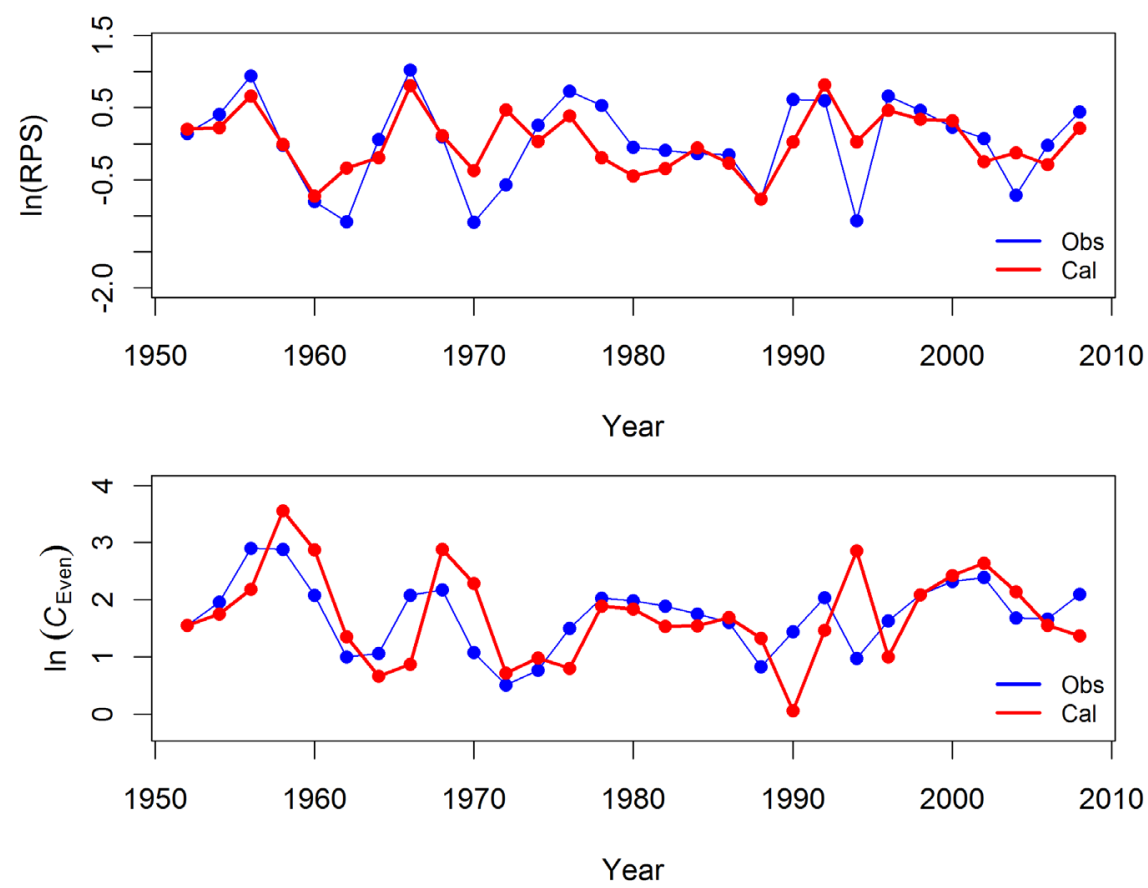

Figure 7. Trajectories of $C_{t+2} / C_{t}$ and $C_{t+2}$ for even-numbered years. Top: $C_{t+2} / C_{t}$ reproduced by the model shown in Equation (1). Bottom: $C_{t+2}$ reproduced by Equation (2).

are also shown at the bottom of Figure 7. The $\ln \left(R P S_{t}\right)$, which is defined by the ratio of the catch, $\ln \left(C_{t+2} / C_{t}\right)$, in both odd- and even-numbered years, was well reproduced only by these environmental factors, and no density-dependent effect seems to exist in the RPS in both sets of years. 


\section{Discussion}

The relationships of the catches between $C_{t+2}$ and $C_{t}$, which corresponds to the SRR, for the populations born in odd- and even-numbered years were similar, and no density-dependent effect was detected. That is, when the simple regression analysis was applied, the slopes of the regression lines were statistically less than unity; however, when Deming and Passing and Bablok regression analyses were applied, the slopes of the regression lines were not statistically different from unity. That is, SRR can be expressed by a simple proportional model, and the differences from the line can be explained by environmental factors, as Sakuramoto insisted [11] [12].

The ratio of the catch, $C_{t+2} / C_{t}$, which corresponds to the RPS, was well reproduced using only environmental factors for both odd- and even-numbered years. This means that the RPS can be reproduced using only the environmental factors, and no density-dependent effect operates in either odd- or even-numbered years. The results coincided well with those for the Pacific stock of Japanese sardines [10] and Pacific bluefin tuna [12].

AO was selected as the only environmental factor when the model was applied to the odd-numbered years. In contrast, AO in year $t$ was not selected and PDO in years $t$ and $t-2$ was selected when the model was applied to the even-numbered years. AO in February in year $t-2$ was selected for both the models; however, the signs in the partial coefficients were opposite, i.e., the value was negative for odd-numbered years and positive for even-numbered years.

In Figure 3 and Figure 4, the directions of the loops that appeared in the plots for $\ln \left(C_{t+2}^{O}\right)$ against $\ln \left(C_{t}^{O}\right)$, which corresponds to the relationship between $\ln \left(R_{t+2}\right)$ against $\ln \left(S S B_{t}\right)$, were opposite for odd- and even-numbered years. According to Sakuramoto [8] [10] [11], the appearance of a clockwise loop in oddnumbered years is reasonable, because the age at maturity is short compared to the cycle of the fluctuation in environmental factors. However, for even-numbered years, an anti-clockwise loop appeared, and this conflicts with the theory proposed by Sakuramoto [8] [10] [11]. This phenomenon is considered to occur when the Rs for odd- and even-numbered years have a negative correlation. When the $\mathrm{R}$ for odd-numbered years has the trajectory of a clockwise loop, and the $\mathrm{R}$ for even-numbered years has a negative correlation with odd-numbered years, the trajectory of SRR for even-numbered years shows an anti-clockwise loop.

The mechanism is illustrated in Figure 8. As Sakuramoto [11] noted, the direction of $R$ and SSB on the SRR plane was determined by the vectors of both $R$ and SSB. When SRR for fish species A has a clockwise loop, the combination of the vectors of $\mathrm{R}$ and SSB shows terms 1, 2, 3 and 4 in the order shown in Figure 8. Then the resultant trajectory results in a clockwise loop. However, when the $\mathrm{R}$ for fish species $B$ has a strong negative correlation with that of species $\mathrm{A}$, the direction of $R$ for species $B$ is opposite that for species $A$. Therefore, in term 1 , the direction of $\mathrm{R}$ is opposite that for species $\mathrm{A}$, and the resultant direction of the combined vectors of $\mathrm{R}$ and SSB is southeast, as shown at the bottom of Figure 8 . 


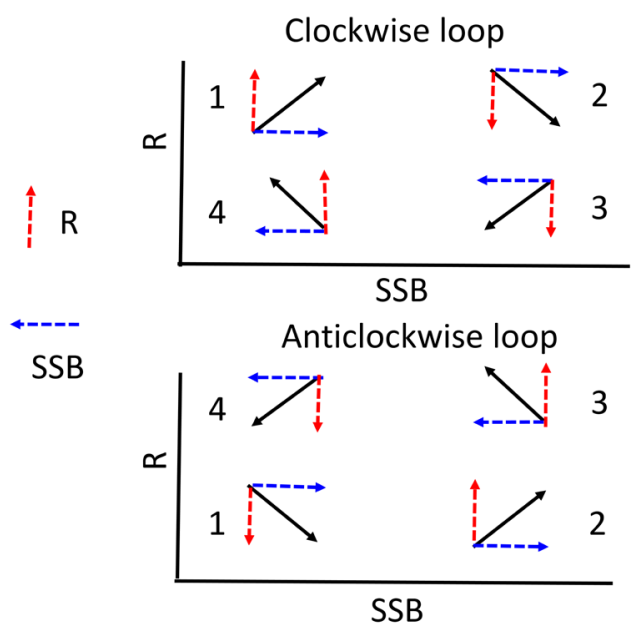

Figure 8. Mechanisms that produce the clockwise or anticlockwise loops. Top: The terms $1,2,3$ and 4 pass in order, and a clockwise loop emerges on the SRR plane. Bottom: The terms 1, 2, 3 and 4 shown at the top correspond to 1, 2, 3 and 4 shown at the bottom, respectively. The direction of the $\mathrm{R}$ in each term is the opposite direction of that shown in the Top, respectively. Then an anticlockwise loop emerges on the SRR plane.

In term 2 , the direction of $\mathrm{R}$ is opposite that for species $\mathrm{A}$, and the resultant direction of the combined vectors of R and SSB is northeast. In terms 3 and 4, the mechanisms are the same, and the resultant directions of the combined vectors of R and SSB are northwest and southwest, respectively. That is, when time passes from term 1 to term 4 , the resultant trajectory of the SSR forms an anticlockwise loop. The opposite case can also occur. That is, the true trajectory of SRR for fish species $\mathrm{C}$ shows an anticlockwise loop, and the $\mathrm{R}$ for fish species $\mathrm{D}$ has a strong negative correlation with that for species $C$; thus, the trajectory of SRR for species D forms a clockwise loop. However, according to the theory proposed by Sakuramoto [8] [10] [11], the former case is considered to be realistic.

The catches born in odd- and even-numbered years have a negative relationship with each other. There might be cannibalism between the pink salmon born in odd-numbered years and those born in even-numbered years. That is, the fries born in even-numbered year $t+1$ may be eaten by one-year old fish born in odd-numbered year $t$, and fries born in odd-numbered year $t$ might be eaten by the one-year old fish born in even-numbered year $t-1$. Whether it is true or not has not been investigated at this stage; therefore, further investigation is necessary to elucidate this possibility. However, it must be true that the negative relationship between the catches born in odd- and even-numbered years would be a key factor in understanding the fluctuation mechanism in the pink salmon population.

In this study, we did not discuss the effect of fries that have been artificially released. However, this effect is considered to be negligible, because Morita et al. [25] concluded that the recent increase in the catch of Japanese pink salmon could be largely explained by climate change, and that increased hatchery releases had little effect. 


\section{Conclusions}

1) We discussed the SRR under the assumption that $C_{t}$ and $C_{t+2}$ were proportional to $S S B_{t}$ and $R_{t+2}$, and analyzed the relationship between the catches as the SRR. The results indicate that no density-dependent effects were detected in SRR for the pink salmon born in both odd- and even-numbered years.

2) The fluctuation of the catch ratio of the pink salmon born in odd- and even-numbered years can be well reproduced by the model that is described by the following equation:

$$
C_{t+2} / C_{t}=g \text { (environmental factors) }
$$

Here we assumed that $C_{t+2} / C_{t}$ represents RPS. That is, RPS can be reproduced only by environmental factors. This result coincides well with those obtained and analyzed by Sakuramoto [11] with regard to the Pacific stock of Japanese sardines and Pacific bluefin tuna.

3) The relationships between the catches of pink salmon born in odd- and even-numbered years were negative, which is a key factor in understanding the fluctuation mechanism in the pink salmon population.

\section{Acknowledgements}

We thank Dr. Rikio Sato for their useful comments, which improved this manuscript.

\section{References}

[1] Ricker, W.E. (1954) Stock and Recruitment. Journal of the Fisheries Research Board of Canada, 11, 559-623. https://doi.org/10.1139/f54-039

[2] Beverton, R.J.H. and Holt, S.J. (1957) On the Dynamics of Exploited Fish Populations. Gt Britain Fish Invest. Ser. 2, Vol. 19, 1-533.

[3] Zhenming, S., Peterman, R.M. and Haeseker, S.L. (2004) Spatial Hierarchical Bayesian Models for Stock-Recruitment Analysis of Pink Salmon (Oncorhynchus gorbuscha). Canadian Journal of Fisheries and Aquatic Sciences, 61, 2471-2486. https://doi.org/10.1139/f04-168

[4] Kaeriyama, M., Seo, H. and Kudo, H. (2009) Trends in Run Size and Carrying Capacity of Pacific Salmon in the North Pacific Ocean. NPAFC Bull No. 5, 293-302.

[5] Springera, A.M. and Vlietb, G.B. (2014) Climate Change, Pink Salmon, and the Nexus between Bottom-Up and Top-Down Forcing in the Subarctic Pacific Ocean and Bering Sea. Proceedings of the National Academy of Sciences of the United States of America, 111, 1880-1888. https://doi.org/10.1073/pnas.1319089111

[6] Beamish, R.J. and Bouillon, D.R. (1993) Pacific Salmon Production Trends in Relation to Climate. Canadian Journal of Fisheries and Aquatic Sciences, 50, 1002-1016. https://doi.org/10.1139/f93-116

[7] Myers, R.A. and Cadigan, N.G. (1993) Density-Dependent Juvenile Mortality in Marine Demersal Fish. Canadian Journal of Fisheries and Aquatic Sciences, 50, 1576-1590. https://doi.org/10.1139/f93-179

[8] Sakuramoto, K. (2005) Does the Ricker or Beverton and Holt Type of Stock-Recruitment Relationship Truly Exist? Fisheries Science, 71, 577-592.

https://doi.org/10.1111/j.1444-2906.2005.01002.x 
[9] Sakuramoto, K. (2013) A Recruitment Forecasting Model for the Pacific Stock of the Japanese Sardine (Sardinops melanostictus) That Does Not Assume DensityDependent Effects. Agricultural Sciences, 4, 1-8. https://doi.org/10.4236/as.2013.46A001

[10] Sakuramoto, K. (2013) A Common Concept of Population Dynamics Applicable to Both Thrips imaginis (Thysanoptera) and the Pacific Stock of the Japanese Sardine (Sardinops melanostictus). Fisheries and Aquaculture Journal, 4, 085. https://doi.org/10.4172/2150-3508.1000085

[11] Sakuramoto, K. (2015) Illusion of a Density-Dependent Effect in Biology. Agricultural Sciences, 6, 479-488. https://doi.org/10.4236/as.2015.65047

[12] Sakuramoto, K. (2016) A Simulation Model of the Spawning Stock Biomass of Pacific Bluefin Tuna and Evaluation of Fisheries Regulations. American Journal of Climate Change, 5, 245-260. https://doi.org/10.4236/ajcc.2016.52021

[13] NPAFC. NPAFC Statistics: Pacific Salmonid Catch and Hatchery Release Data. http://www.npafc.org/new/science_statistics.html

[14] NOAA Climate Prediction Center. Arctic Oscillation (AO). http://www.cpc.ncep.noaa.gov/products/precip/CWlink/daily_ao_index/monthly.a o.index.b50.current.ascii

[15] NOAA's National Centers for Environmental Information. Pacific Decadal Oscillation (PDO). https://www.ncdc.noaa.gov/teleconnections/pdo/

[16] Deming, W.E. (1943) Statistical Adjustment of Data. Dover Publication Inc., New York.

[17] Passing, H. and Bablok, W. (1983) New Biometrical Procedure for Testing the Equality of Measurements from Two Different Analytical Methods. Application of Linear Regression Procedures for Method Comparison Studies in Clinical Chemistry. Journal of Clinical Chemistry \& Clinical Biochemistry, 21, 709-720.

[18] Maelezer, D.A. (1970) The Regression of $\log N_{i+1}$ on $\log N_{i}$ as a Test of Density Dependence: An Exercise with Computer-Constructed Density-Dependent Populations. Ecology, 51, 810-822. https://doi.org/10.2307/1933973

[19] Kuno, E. (1971) Sampling Error as a Misleading Artifact in "Key Factor Analysis". Researches on Population Ecology, 8, 28-45. https://doi.org/10.1007/BF02522011

[20] Ito, Y. (1972) On the Methods for Determining Density-Dependence by Mean of Regression. Oecolagia, 10, 347-372. https://doi.org/10.1007/BF00345737

[21] Sakuramoto, K. and Suzuki, N. (2012) Effect of Process and/or Observation Errors on the Stock-Recruitment Curve and the Validity of the Proportional Model as a Stock-Recruitment Relationship. Fisheries Science, 78, 41-45. https://doi.org/10.1007/s12562-011-0438-4

[22] Hasegawa, S., Suzuki, N. and Sakuramoto, K. (2015) Performance of Deming and Passing Bablok Regression Analysis in Detecting Proportionality in the Stock-Recruitment Relationship. Asian Fisheries Science, 28, 102-116.

[23] Aoki, S. (2009) Parameter of a Regression Line Estimated by Deming Regression Method. http://aoki2.si.gunma-u.ac.jp/R/Deming.html

[24] Aoki, S. (2009) Parameter of a Regression Line Estimated by Passing Bablok Regression Method. http://aoki2.si.gunma-u.ac.jp/R/PassingBablok.html

[25] Morita, K., Morita, S.H. and Furuwaka, M. (2006) Population Dynamics of Japanese Pink Salmon (Oncorhynchus gorbuscha): Are Recent Increases Explained by Hatchery Programs or Climatic Variations? Canadian Journal of Fisheries and Aquatic Sciences, 63, 55-62. https://doi.org/10.1139/f05-207 
Submit or recommend next manuscript to OALib Journal and we will provide best service for you:

- Publication frequency: Monthly

- 9 subject areas of science, technology and medicine

- Fair and rigorous peer-review system

- Fast publication process

- Article promotion in various social networking sites (LinkedIn, Facebook, Twitter, etc.)

- Maximum dissemination of your research work

Submit Your Paper Online: Click Here to Submit

Or Contact service@oalib.com 